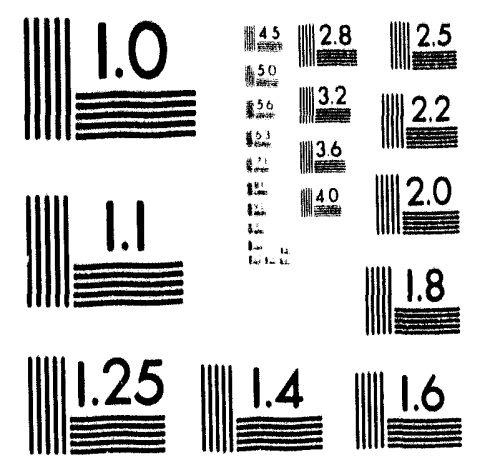


LA-UR- 93-3304

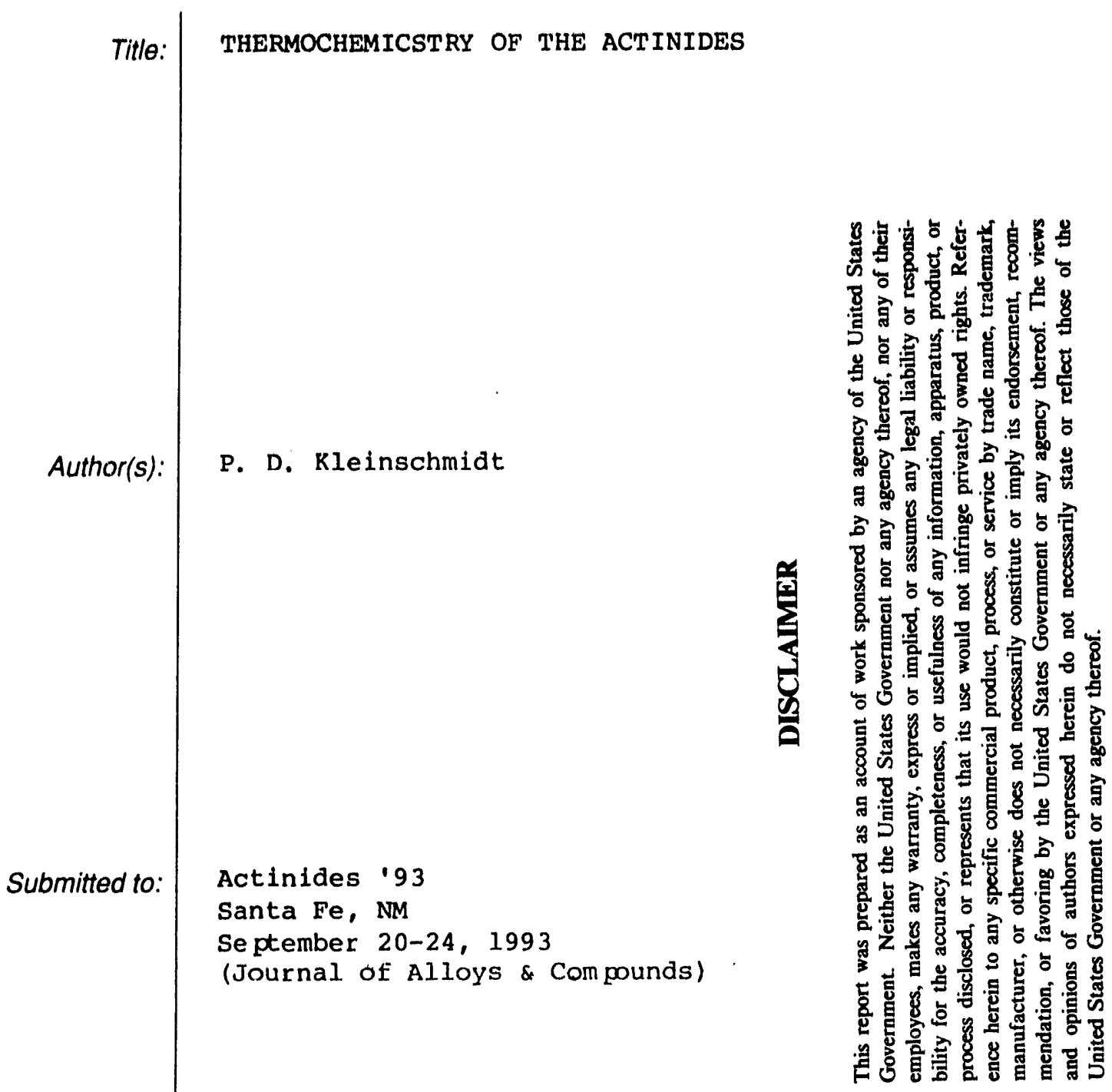

Cof $1950505-10$
UEIVED

OCT 071993

OSTI

\section{Los Alamos}

NATIONAL LABORATORY

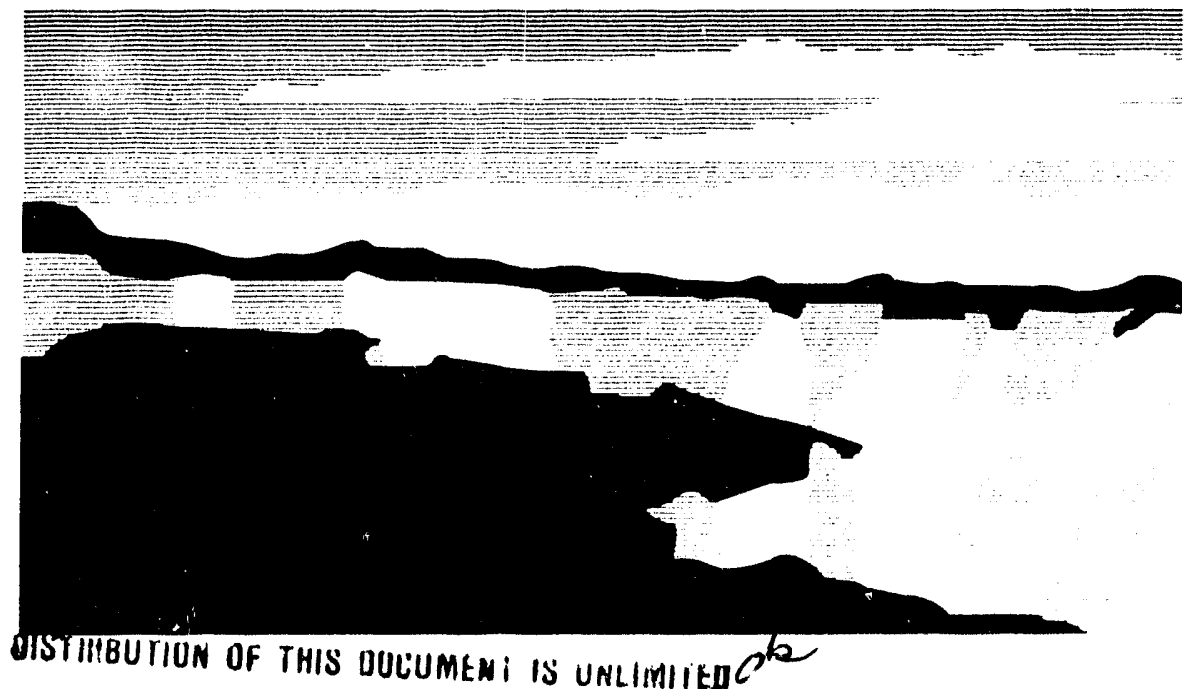

Los Alamos National Laboratory, an aftirmative action/equal opportunity emplóyer, is operated by the University of California for the U.S. Department of Energy under contract W-7405-ENG-36. By acceptance of this article, the publisher recognizes that the U.S. Government retains a nonexclusive, royalty-free license to publish or reproduce the published form of this contribution, or to allow others to do so, for U.S. Government purposes. The Los Alamos National Laboratory requests that the publisher identify this article as work pertormed under the auspices of the U.S. Department of Energy. 


\section{THERMOCHEMISTRY OF THE ACTINIDES}

by

Phillip D. Kleinschmidt

Person to whom correspondence should be addressed:

Phillip D. Kleinschmidt

MS G-730

Los Alamos National Laboratory

Los Alamos, NM 87545

U.S.A.

Phone: (505)-667-6945

FAX \#1: (505)-667-8021

FAX \#2: (505)-665-4459 


\title{
THERMOCHEMISTRY OF THE ACTINIDES
}

\author{
Phillip D. Kleinschmidt \\ Actinide Material Chemistry \\ Nuclear Materials Chemistry Division \\ Los Alamos National Laboratory \\ Los Alamos, NM 87545
}

\begin{abstract}
KEYWORDS
actinides, fluorides, thermodynamics, sublimation, enthalpy of formation, entropy

ABSTRACT

The measurement of equilibria by Knudsen effusion techniques and the enthalpy of formation of the actinide atoms is briefly discussed. Thermochemical data on the sublimation of the actinide fluorides is used to calculate the enthalpies of formation and entropies of the gaseous species. Estimates are made for enthalpies and entropies of the tetrafluorides and trifluorides for those systems where data is not available. The pressure of important species in the tetrafluoride sublimation processes is calculated based on this thermochemical data.
\end{abstract}

\section{INTRODUCTION}

Thermochemical data for the actinide series is sparse when compared with other elements in periodic table (see for example the tables in [1]). This is due to the small quantities of elements available as samples, special precautions and hazards, short half lives, and difficulty in obtaining reliable thermochemical data from small quantities of materials. It is therefore necessary to extrapolate and estimate thermodynamic functions as a function of atomic number. This paper will examine trends in the enthalpy and entropy of gaseous and solid actinide fluorides. These quantities will be related to measured enthalpies and entropies of sublimation and to dissociation energies. 


\section{THERMOCHEMICAL MEASUREMENTS}

Thermochemical data is obtained from calorimetry, measurement of equilibria with the gas phase, and emf measurements [1]. This paper covers equilibria with the gas phase by measurement of the rate of evaporation from an effusion cell. Free energy changes for chemical reactions are related to measured rates of evaporation or pressure. The free energy change, $\Delta G$, for a given process at a temperature, $T$, is related to the enthalpy,

$\triangle H$, and entropy, $\triangle S$, changesand to the equilibrium constant, $K$, for a reaction by the equations:

$$
\Delta G=\Delta H-T \Delta S=-R T \ln K
$$

where $\mathbf{R}$ is the gas constant. In reactions in which a solid is in equilibrium with a single gas phase species the equilibrium constant reduces to $P$, the pressure of the species.

Measuring the pressure of an atom, $\mathrm{A}$, in the simple sublimation reaction:

$$
A(s, 1)=A(g)
$$

gives one the free energy of formation of $A(8)$. Similarly measuring the pressure of molecule $A X_{n}$ in the reaction:

$$
A X_{n}(s, l)=A X_{n}(g)
$$

gives one the free energy of sublimation of $\operatorname{AX}_{n}(s)$. This data is combined with the dissociation energy, $D_{0}$, of $A_{X_{n}}(g)$, the free energy of formation of the atoms $A(g)$ and $X(g)$, and the free energy of formation of $\mathrm{AX}_{\mathrm{n}}(\mathrm{s})$ in a thermochemical cycle. The quantity $D_{0}$ refers to the enthalpy change at $0 \mathrm{~K}$ for the reaction:

$$
A X_{n}(g)=A(g)+n X(g)
$$


In the Knudsen effusion technique [1], the pressure is proportional to the rate of loss of material from the cell. This rate is determined by weighing the cell, condensing the beam on a target, or by detecting the effusing beam with a mass spectrometer.

The relation between the pressure, $P$, of a gas phase species and an ion current, $\mathrm{I}^{+}$it produces in a mass spectrometer is:

$$
\mathrm{p}=\mathrm{CI}^{+} \mathrm{T}
$$

where $C$ is an instrumental constant depending on the geometry of the system, the ionization cross section, the detector efficiency, the electron beam energy and the appearance potential of the detected species $\mathrm{AnX}_{\mathrm{m}}{ }^{+}$. With the use of an electron impact ion source on the mass spectrometer, one can also obtain thermochemical data by measuring ionization and fragment ion appearance potentials.

\section{ACTINIDE ELEMENTS}

Measurement of the enthalpy of sublimation of the actinide elements gives one the cohesive energy of the metals (the energy difference between the gaseous atoms and the metal). Shown in Figure $l$ is the enthalpy of formation of the gaseous atoms $[2,3]$. The enthalpy of formation of the atoms is equal to the enthalpy of sublimation.

Only actinium and the elements beyond mendelevium have not been measured. The cohesive energy of the early actinides has a contribution from $f$ electron bonding. After $\mathrm{Pu}$ in the periodic table this effect is not present and the series behaves like the lanthanides until Es is reached. At Es the metal becomes divalent like Ba. Since not all gas phase atoms are in the same valence state as they are in the metal, a correction equal to the excitation energy to the trivalent state is added to the enthalpy of sublimation [4]. 
The constancy of this function is apparent in the part of the series running from Am to Cf, the region in which the metals should be trivalent. The entropies of the actinide atoms have been calculated from the electronic energy levels of the atoms [2].

\section{ACTINIDE FLUORIDES}

The actinide fluorides have the largest enthalpies of formation of the actinide halides and they can have valences up to six for the $\mathrm{U}, \mathrm{Np}$, and $\mathrm{Pu}[5,6]$. Sublimation data is available for $\mathrm{UF}_{6}$ [5], $\mathrm{NpF}_{6}$ [5], $\mathrm{PuF}_{6}$ [5], $\mathrm{ThF}_{4}$ [7], UF 4 [8], NpF 4 [9], PuF 4 [10], $\mathrm{PuF}_{3}[11], \mathrm{AmF}_{3}$ [12], and $\mathrm{CfF}_{3}$ [13]. The enthalpy and entropy of sublimation for the reaction:

$$
A_{n} F_{n}(s)=A n F_{n}(g)
$$

is given in Table 1 where $n=3$ and 4 .

The enthalpy of formation of solid actinide fluorides is shown in Table 2. Most of the enthalpies of formation of the tetrafluorides and trifluorides have been estimated $[5,6]$ Tetrafluorides formed from einsteinium and higher atomic numbered elements are unstable relative to the trifluorides. Thorium and protactinium are not known to form trifluorides.

The entropies of the solid fluorides are shown in Table 3. The entropies of the tetrafluorides and trifluorides which have not been measured are estimated assuming that the spin contribution is the only difference in the entropy in going to heavier elements.

The enthalpy of formation of the gaseous species (shown in Table 4) can be calculated from the enthalpy of formation of the solid and the enthalpy of sublimation. The enthalpy of sublimation has been linearly extrapolated for the trifluorides to the heavier actinides so that the enthalpy of formation of these species can be calculated. 
For those species such as $\mathrm{ThF}_{3}(8)$ which cannot be generated directly by sublimation of a solid, the enthalpy of formation can be calculated from the thermochemical cycle:

$$
\begin{array}{r}
\operatorname{AnF}_{n}(g) \rightarrow A n(g)+F(g) \rightarrow \\
A n(s)+n / 2 F_{2}(g) \rightarrow A n F_{n}(g)
\end{array}
$$

Data needed to complete the cycle besides the enthalpy of formation of $A n F_{n}(8)$ includes the enthalpy of formation of the atoms and the dissociation (atomization) energy. The relationship between the dissociation energy and the enthalpy of formation of $\mathrm{AnF}_{\mathrm{n}}(\mathrm{g})$ is:

$$
\begin{gathered}
\left.\Delta_{f} H\left(A_{n F}, 298\right)=D_{0}+\Delta_{\left(H^{0}(298 K)\right.}-H^{0}(0 K)\right) \\
+\Delta_{f} H^{0}(A n, g)+n / 2 \Delta_{f} H^{0}(X, g)
\end{gathered}
$$

Bond dissociation energies measured from gas phase equilibria $[7,14,16]$ were used to calculate the dissociation energies of the trifluorides and difluorides where known. If the enthalpy of formation is known from sublimation reactions, the dissociation energy can be calculated if the enthalpy of formation of the atoms is known. The entropy of the gaseous species in given in Table 5. For those species for which no information is available in the literature, the entropy has been calculated by assuming that the structure and vibrational frequencies are the same as those given for $\mathrm{UF}_{4}$ or $\mathrm{UF}_{3}[17]$. The atomic weights of the actinide atums are $\mathrm{Pa}=231.0, \mathrm{~Np}=237.0$, $\mathrm{Cm}=248.1, \mathrm{Bk}=249.1$, and $\mathrm{Es}=243.1$. These weights are for isotopes most likely to be used in experiments. The ground state degeneracies were assumed to be $\mathrm{PaF}_{4}-2$, $A \mathrm{AF}_{4}-6, \mathrm{AcF}_{3}-1, \mathrm{PaF}_{3}-3, \mathrm{NpF}_{3}-5, \mathrm{CmF}_{3}-8, \mathrm{BkF}_{3}-7$ and $\mathrm{EsF}_{3}-5$. No excited state electronic contributions were assumed. All the tetrafluoride molecules with the exception of $\mathrm{ThF}_{4}(8)$ were assumed to have $\mathrm{C}_{2 v}$ symmetry. The trifluorides were 
assumed to have $C_{3 v}$ symmetry. The estimated error ranges from $+/-15$ to $+/-20 \mathrm{~J} / \mathrm{K}$ mole.

Based upon the data given here and assuming that the free energy of formation of the species can be approximated by the relation:

$$
\Delta G^{0}(T)=\Delta H^{0}(298 K)-T \Delta S^{0}(298 K)
$$

The vapor species present during sublimation or evaporation can be calculated. The sublimation mechanism for the tetrafluorides is believed to occur in the temperature range 298 to $1000 \mathrm{~K}$ by the following processes:

$$
\begin{gathered}
\mathrm{AnF}_{4}(\mathrm{~s})=\mathrm{AnF}_{4}(\mathrm{~g}) \\
\mathrm{AnF}_{4}(\mathrm{~s})=\mathrm{AnF}_{3}(\mathrm{~s})+\mathrm{F}(\mathrm{g})
\end{gathered}
$$

The first process applies to $\mathrm{Th}, \mathrm{Pa}, \mathrm{U}, \mathrm{Np}$ and $\mathrm{Pu}$ and the second process applies to $\mathrm{Cm}$, Bk, Cf, and Es with Am being an intermediate case.

\section{ACKNOWLEDGEMENTS}

The contributions of Mark Williamson and R. G. Haire are acknowledged for sample preparation and measurements on the $\mathrm{PuF}_{4}$ and $\mathrm{CfF}_{3}$ systems. 


\section{REFERENCES}

1 O. Kubaschewski and C. B. Alcock, Metallurgical Thermochemistry, 5th edn., Pergamon, Oxford, 1979, p. 65.

2 J. W. Ward, P. D. Kleinschmidt, and D. E. Peterson, in A. J. Freeman and C. Keller (eds.), Handbook on the Physics and Chemistry of the Actinides, Vol. 4, North-Holland, Amsterdam, 1986, p. 309.

3 R. G. Haire and J. K. Gibson, J. Chem. Phys, 91, 7085 (1989).

4 P. D. Kleinschmidt, J. W. Ward, G. M. Matlack, and R. G. Haire, High Temperature Science, 19 (1985) 267.

5 J. Fuger, V. B. Parker, W. N. Hubbard, and F. L. Oetting, The Chemistry of the Actinide Elements and Compounds, Part 8 The Actinide Halides, Int. At. Energy Agency, Vienna, 1983.

6 L. R. Morss in J. J. Katz, G. T. Seaborg, and L. R. Morss (eds.) The Chemistry of the Actinide Elements, Vol. 2, chap. 17.

7 K. H. Lau, R. D. Brittain, and D. L. Hildenbrand, J. Chem. Phys. 90 (1989) 1158.

8 D. L. Hildenbrand, J. Chem. Phys. 66 (1977), 4783

9 P. D. Kleinschmidt, K. H. Lau, and D. L. Hildenbrand, J. Chem. Phys. 97 (1992) 1950.

10 P. D. Kleinschmidt and M. A. Williamson, unpublished results.

11 P. D. Kleinschmidt, J. Nucl. Mat. 167 (1989) 131.

12 S. C. Carniglia and B. B. Cunningham, JACS 77 (1955), 1451.

13 P. D. Kleinschmidt, M. A. Williamson and R. G. Haire, unpublished results.

14 P. D. Kleinschmidt, J. Chem. Phys. 89 (1988), 6897.

15 K. H. Lau and D. L. Hildenbrand, J. Chem. Phys. 76 (1982), 2646

16 D. L. Hildenbrand, L. V. Gurvich, and V. S. Yungman, The Chemical

Thermodynamics of Actinide Elements and Compounds, Part 13 The Gaseous Actinide Ions, Int. At. Eng. Agency, Vienna, 1985.

17 L. V. Gurvich, V. S. Yungman, O. V,. Dorofeyeva, L. N. Gorokhov, and S. S. Munvez, The Thermodynamic Properties of Gaseous W-F and U-F Systems, in Proceedings of the VIIth Symposium on Thermophysical Properties, U. S. Natl. Bur. Stand. May 1977. 
Table 1. Enthalpy and Entropy of Sublimation of Actinide Tetrafluorides and Trifluorides at $298 \mathrm{~K}$.

\begin{tabular}{|c|c|c|c|c|c|}
\hline$A \cap F_{n}$ & $\Delta_{k \mu} \rho^{l}$ & $\begin{array}{l}(298) \\
\text { lo }\end{array}$ & $\Delta_{\text {puk }}{ }^{S}$ & $\begin{array}{l}\text { 298) } \\
\text { ole }\end{array}$ & Ref. \\
\hline $\mathrm{ThF}_{4}$ & 338.4 & +4.0 & 203.1 & +4.0 & [7] \\
\hline $\mathrm{PaF}_{4}$ & (326. & +20)$. & (215. & +13)$. & est. \\
\hline$U F_{4}$ & 318.8 & +2.1 & 218.2 & +6.3 & [8] \\
\hline $\mathrm{NpF}_{4}$ & 288.1 & +3.6 & 199.1 & +11.0 & [9] \\
\hline PuF $_{4}$ & 286.0 & +2.1 & 192.9 & +2.4 & [10] \\
\hline $\mathrm{AmF}_{4}$ & (269. & +20)$. & $(211$. & +13)$. & est. \\
\hline $\mathrm{PuF}_{3}$ & 429.5 & +4.7 & 209.7 & +3.3 & [11] \\
\hline $\mathrm{AmF}_{3}$ & 427.7 & +2.2 & 213.3 & +1.7 & [12] \\
\hline $\mathrm{CmF}_{3}$ & (426. & +20)$. & (214. & +21)$. & est. \\
\hline $\mathrm{BkF}_{3}$ & (424. & +20)$. & $(214$. & +21)$. & est. \\
\hline $\mathrm{CfF}_{3}$ & 430.9 & +5.4 & 212.9 & +4.3 & [13] \\
\hline $\mathrm{EsF}_{3}$ & (420. & +20)$. & (215. & +21)$. & est \\
\hline
\end{tabular}


Table 2. Enthalpy of Formation, $\Delta H^{0}\left(A_{n F}, s, 298\right)$, of Solid Actinide Fluorides. Values in $\mathrm{kJ} / \mathrm{mole}$.

\begin{tabular}{|c|c|c|c|c|c|c|}
\hline An & $A \cap F_{6}$ & & \multicolumn{2}{|c|}{$A \cap F_{4}$} & $A \cap F_{3}$ & \\
\hline Ac & $\bullet$ & & - & & $(-1659$ & Ms. $)^{(5)}$ \\
\hline Th & $\bullet$ & & -2098. & $+8 .(5,6)$ & $\bullet$ & \\
\hline $\mathbf{P a}$ & $\bullet$ & & $(-1946$ & +17.\rangle^{(5,6)}$ & $\bullet$ & \\
\hline $\mathbf{U}$ & -2197 & $+2 .(5,6)$ &.-1914. & $+4(5,6)$ & -1502. & $+4.15,6)$ \\
\hline Np & - & & $(-1874$ & +13.)^{(5,6)}$ & $(-1530$ & +5.)^{(5,6)}$ \\
\hline Pu & -2025. & +42.14 & $(-1846$ & +21,)^{[5,6]}$ & -1586. & $+3,(5,6)$ \\
\hline Am & $\bullet$ & & $(-1720$ & +29.)^{[5,6]}$ & (- 1508 & $+13, \psi^{(5,6)}$ \\
\hline $\mathrm{Cm}$ & $\bullet$ & & $(-1689$ & $f^{(6)}$ & $(-1599$ & $+18 . y^{(6)}$ \\
\hline Bk & $\bullet$ & & $(-1793)$ & $\psi^{(6)}$ & $(-1581$. & $f^{(0)}$ \\
\hline $\mathrm{Cr}$ & $\bullet$ & & $(-1623$ &.$^{(6)}$ & $(-1553$ & +35.\rangle^{|6|}$ \\
\hline Es & $*$ & & $(-152)$ & $f^{[6]}$ & $(-1575$ & $+40 . j^{|6|}$ \\
\hline
\end{tabular}

( ) - estimate, - not stable, - - data not available 
Table 3. Entropy, $\mathrm{s}^{\circ}\left(\mathrm{AnF}_{\mathrm{n}}, \mathrm{s}, 298\right)$, of Solid Actinide Fluorides. Values in $\mathrm{J} / \mathrm{K}$ mole.

\begin{tabular}{|c|c|c|c|c|c|c|}
\hline An & $\mathrm{AnF}_{6}$ & $J / K$ & $e^{A n F_{4}}$ & & $\mathrm{AnF}_{3}$ & \\
\hline Ac & $\bullet$ & & $\bullet$ & & (112. & +6)$. \\
\hline Th & $\bullet$ & & 142.0 & $+0.2^{[5,6]}$ & * & \\
\hline Pa & - & & $(146.9$ & +4.)^{[5,6]}$ & * & \\
\hline $\boldsymbol{U}$ & 227.6 & $+13 .[5,6]$ & 151.7 & $+0.2^{[5,6]}$ & 123.4 & $+0.4^{[5,6]}$ \\
\hline Np & 229.1 & $+0.5^{[6]}$ & (153. & +4.)^{\lfloor 5,6]}$ & 125. & $+4 .^{[5,6]}$ \\
\hline $\mathbf{P u}$ & 222. & $+21^{[6]}$ & 147.2 & $+0.4^{[5,6]}$ & 126.1 & $+0.4^{[5,6]}$ \\
\hline Am & - & & (148.5 & +4.)^{[5,6]}$ & $(128$. & +4.)^{[5,6]}$ \\
\hline $\mathrm{Cm}$ & • & & (150. & +6)$. & (12.9. & +6)$. \\
\hline Bk & • & & $(151$. & +6)$. & $(128$. & +6)$. \\
\hline $\mathrm{Cr}$ & - & & $(150$. & +6)$. & (126. & +6)$. \\
\hline Es & - & & (149. & +6)$. & $(125$. & +6)$. \\
\hline
\end{tabular}

( ) - estimated value, * - not stable, - = data not available 
Table 4. Enthalpy of Formation, $\triangle_{n} H^{0}\left(A_{n F}, 8,298\right)$, of Gaseous Actinide Fluorides. Values in $\mathrm{kJ} / \mathrm{mole}$.

\begin{tabular}{|c|c|c|c|c|c|c|}
\hline An & $\mathrm{AnF}_{4}$ & & $\mathrm{AnF}_{3}$ & & $\mathrm{AnF}_{2}$ & \\
\hline Ac & $*$ & & - & & - & \\
\hline Th & -1759.0 & $+4 .^{[7]}$ & -1171.5 & $+12 .^{[7]}$ & -597.9 & $+10 . .^{[7]}$ \\
\hline $\mathrm{Pa}$ & $(-1620$ & +26)$. & - & & - & \\
\hline $\mathbf{U}$ & -1602.9 & $+4.6^{[15]}$ & -1084.9 & $+12.6^{[15]}$ & -540.6 & $+10.5^{[15]}$ \\
\hline $\mathrm{Np}$ & -1586 & $+17 .^{[9]}$ & $(-1099$ & +21)$. & - & \\
\hline $\mathbf{P u}$ & -1560 & $+21]^{[10]}$ & -1156 & $+6 .^{[11]}$ & -615.8 & $+21{ }^{[16]}$ \\
\hline Am & $(-1451$ & +35)$. & -1160. & $+13 .^{[12]}$ & - & \\
\hline $\mathrm{Cm}$ & - & & $(-1173$ & +27)$. & - & \\
\hline Bk & - & & $(-1157$ & +35)$. & - & \\
\hline $\mathrm{Cf}$ & - & & -1102 & $+35^{[13]}$ & - & \\
\hline Es & - & & $(-1155$ & +45)$. & - & \\
\hline
\end{tabular}

$(\quad$ ) = estimated value, * = not stable, - = data not available 
Table 5. Entropy, $S^{\circ}\left(A_{n F}, 8,298\right)$, of Gaseous Actinide Fluorides. Values in $J / K$ mole.

\begin{tabular}{|c|c|c|c|c|c|c|}
\hline An & $\mathrm{AnF}_{4}$ & & $\mathrm{AnF}_{3}$ & & $\mathrm{AnF}_{2}$ & \\
\hline Ac & * & & (324.9 & +20)$. & - & \\
\hline Th & 345.1 & $+4\left[{ }^{[7]}\right.$ & 335.4 & $+12 .^{[7]}$ & 297.9 & $+10 .[7]$ \\
\hline $\mathbf{P a}$ & (362. & +15)$. & (334. & +20)$. & - & \\
\hline $\mathbf{U}$ & 364.4 & $+4.2^{[15]}$ & 355.3 & $+20 .[15]$ & 328.0 & $+12 .^{[15]}$ \\
\hline $\mathbf{N p}$ & 351.8 & $+12 .[9]$ & (339. & +20)$. & - & \\
\hline $\mathbf{P u}$ & 340.2 & $+2.4^{[10]}$ & 335.8 & $+3.3^{[11]}$ & 297. & [16] \\
\hline Am & $(360$. & +15)$. & 340.9 & $+4.3^{[12]}$ & - & \\
\hline $\mathrm{Cm}$ & - & & (343. & +20)$. & - & \\
\hline Bk & - & & (342. & +20)$. & - & \\
\hline Cf & - & & 339.4 & $+5 . g^{[13]}$ & - & \\
\hline Es & - & & $(340$. & +20)$. & - & \\
\hline
\end{tabular}

$(\quad$ ) = estimated value, * = not stable, - - data not available 
FIGURES

1. Enthalpy of Sublimation of the Elements 


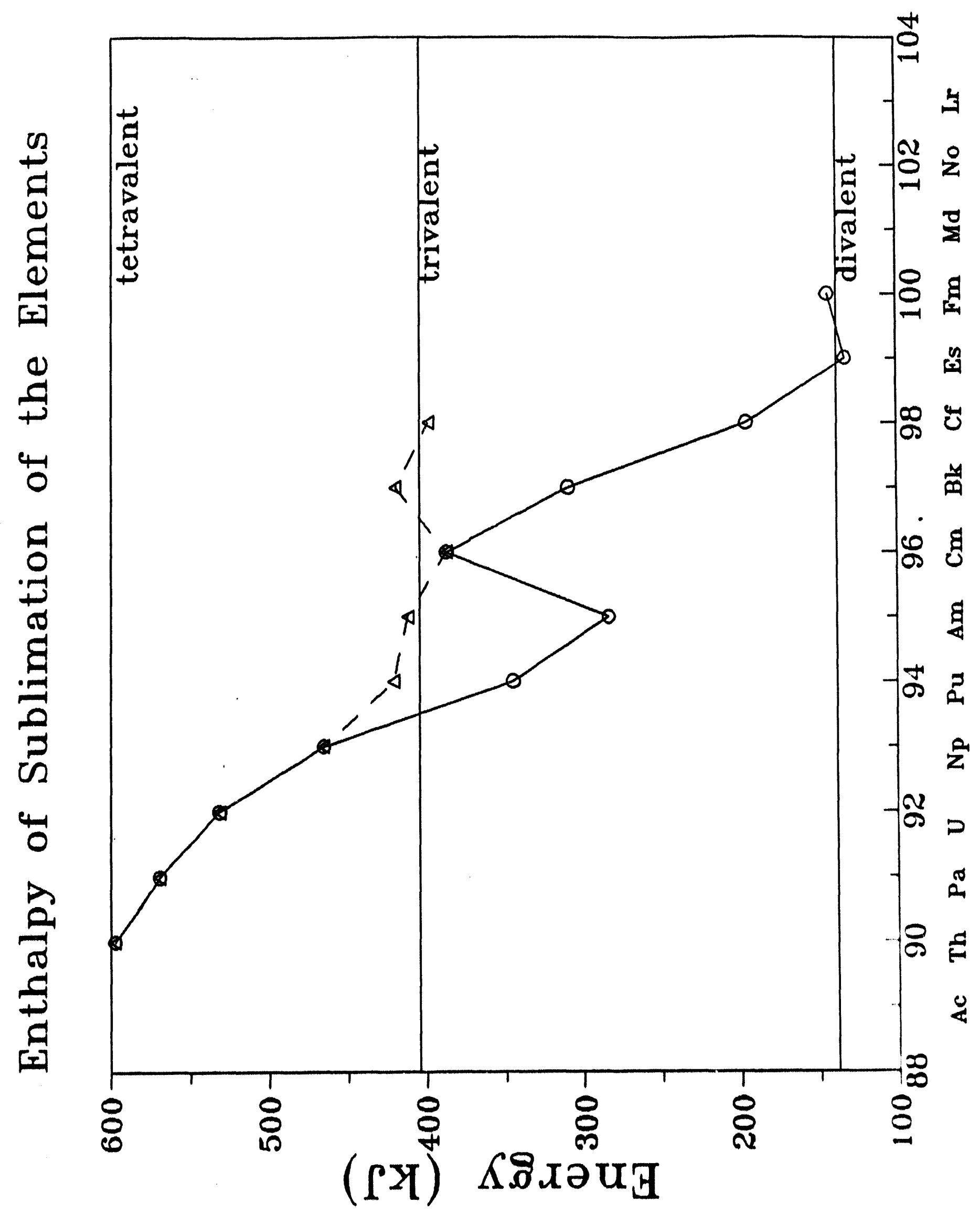




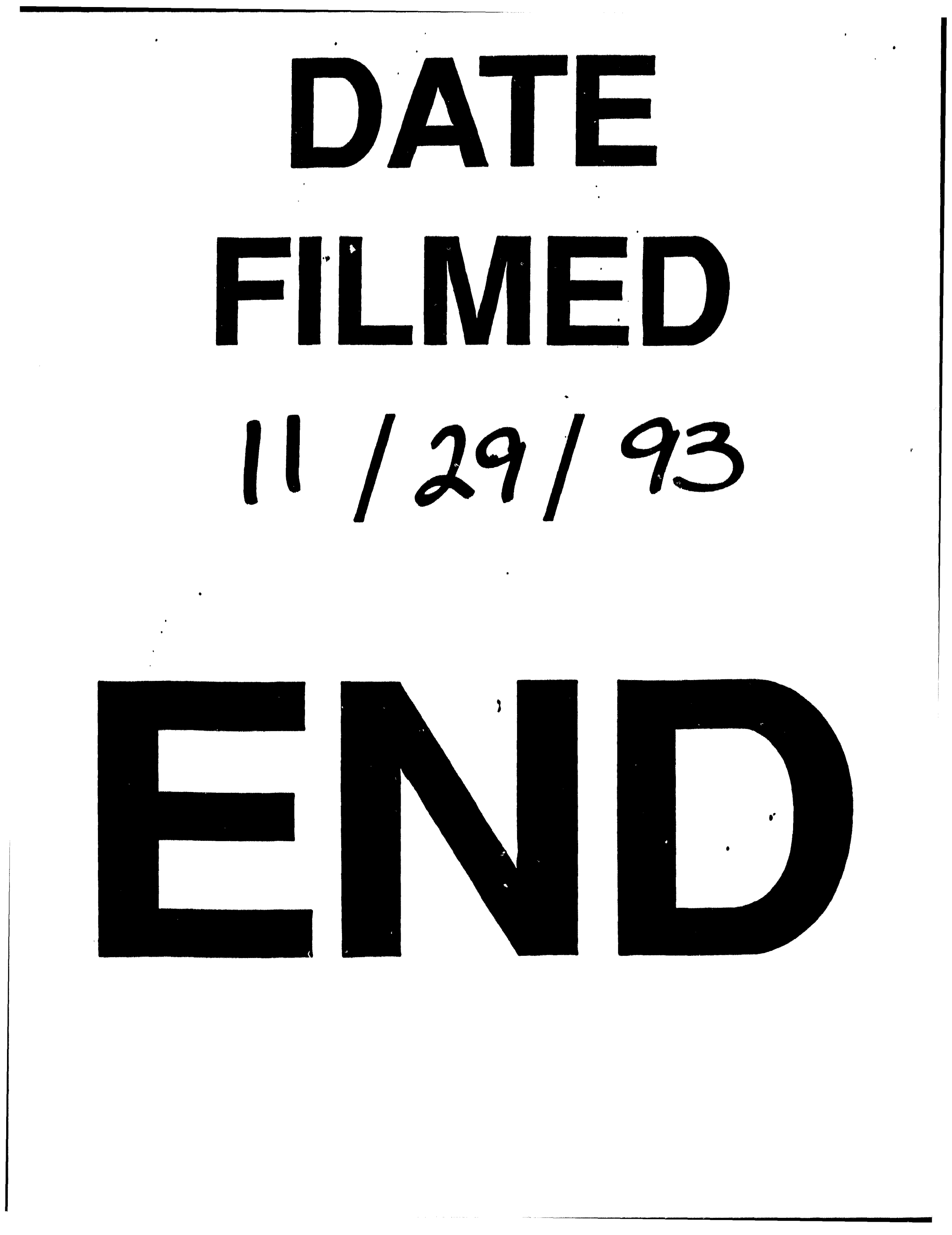




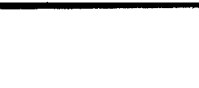

$$
-
$$

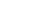


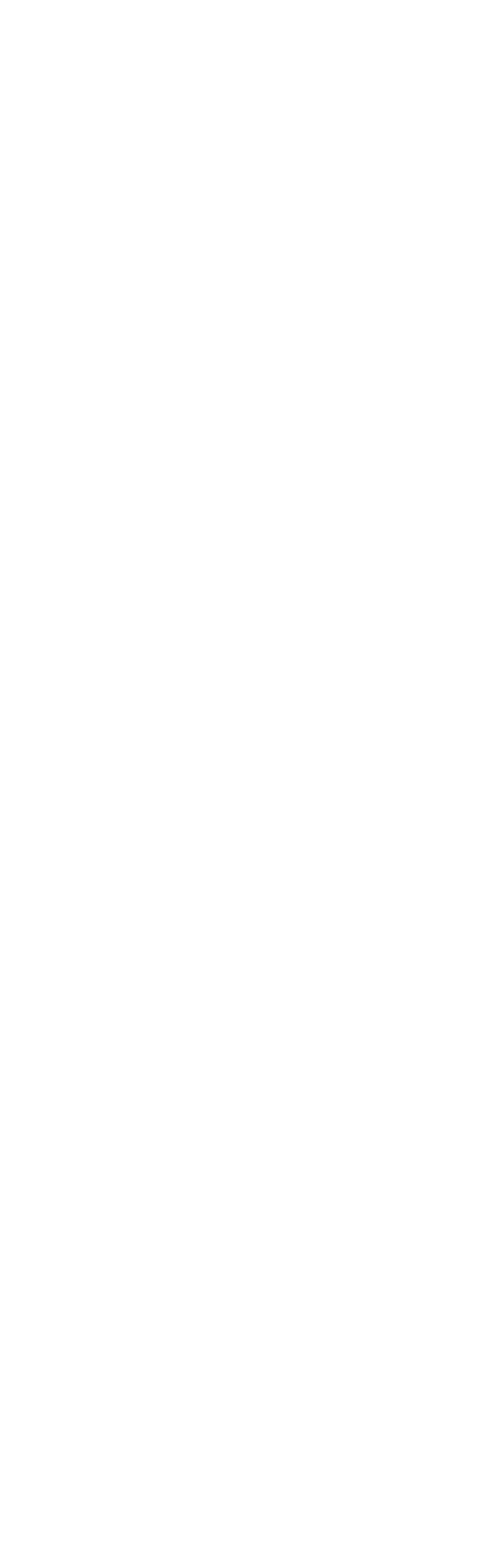
( 